\title{
CARTA DOS EDITORES CONVIDADOS
}

\section{Eugenesia en la Europa mediterránea y en Latinoamérica}

En los últimos años, los estudios sobre el desarrollo internacional de la eugenesia han cobrado un impulso particular. En elcontexto centrado en Europa mediterránea y en Latinoamérica, los trabajos precursores de Nancy Stepan (1991), Anne Carol (1995) y Raquel Álvarez Peláez (1999) permitieron abrir una especie de "caja de Pandora" al detectar fuentes y construir nuevas miradas sobre fuentes ya conocidas. En efecto, merced al impacto de sus trabajos pioneros fue generándose un creciente interés en el campo de la investigación de esa "ciencia del cultivo de la raza", y, desde los años 1990, los estudios sobre eugenesia dejaron de concentrarse exclusivamente en el mundo anglosajón y en su relación unívoca con los totalitarismos del período entreguerras.

En este sentido, se abordan aquí las vinculaciones inmanentes que la eugenesia presenta con los ejes conceptuales salud/enfermedad, normalidad/anormalidad, inclusión/exclusión, colocando a la perspectiva histórica en un diálogo inacabado con el presente. Así, y desplazándose más allá de una identificación taxativa con episodios que tienen un inicio y un final, quedan latentes interrogantes que denotan los límites borrosos de la eugenesia: ¿Cómo se trazó en distintos momentos la frontera entre lo sano y lo insano? ¿Quién/quiénes y bajo qué motivaciones trascendentes al plano individual la fijaron? ¿Cuáles fueron los alcances de la eugenesia? ¿Cuántos de sus postulados se mantuvieron inalterables en países no anglosajones y hasta dónde las hibridaciones turbaron sus postulados iniciales? En definitiva, ¿Por qué es válido hablar de eugenesia más allá del nazismo?

Aunque a sabiendas que estas preguntas exceden la posibilidad de obtener respuestas inmediatas y acabadas, los trabajos aquí reunidos contribuyen con aportes que nos abren, a su vez, otras nuevas interrogantes, las cuales adquieren una dimensión global descentralizando al mundo anglosajón.

La eugenesia es historizada aquí como expresión de articulaciones entabladas entre ciencia y poder, biología y política, medicina y religión, salud y sexualidad, en el marco de países integrados a través de un diálogo permanente sobre la temática. Desde allí, y a partir de histoires croisées que emergen de manera implícita o explícita, se abordan las especificidades en relación a contextos geográficos y epocales signados por el impacto de la Primera y Segunda Guerra Mundial y la Guerra Fría.

Los textos aquí reunidos revelan una diversidad metodológica y de objetos de estudio, coexistiendo historias que abordan perfiles biográficos; libros y sus recepciones; movimientos contraculturales; organizaciones e instituciones normalizadoras con aquellas que exploran la presencia de la foucaultiana microfísica del poder. 
El marco de la Primera Guerra Mundial y su crisis civilizatoria nos aportan un punto de partida. Allí, emerge la figura del fisiologista y Premio Nobel francés Charles Richet (1919) promoviendo la creación de élites intelectuales a partir de la "selección humana". En ese mismo contexto histórico, anarquistas españoles tensaron los vínculos entre neomalthusianismo y eugenesia desde una crítica sistémica que tenía su costado regenerador de la especie humana. Paralelamente, en la Argentina nacía su primera Sociedad Eugénica, y los debates conformados por el campo científico en torno a este nuevo saber abrirán un abanico de alternativas delimitado con la posterior adhesión a los autoritarismos europeos.

A su vez, el período de entreguerras también nos permite ver la pervivencia tardía del degeneracionismo francés bajo el halo de novedad que traía la eugenesia, tanto en el modo en que en Colombia fueron integrados a la higiene social como en las inquietudes con las que Renato Kehl, en Brasil, formuló su teoría que incluyó la pretensión esterilizadora de criminales. Por su parte, el médico chileno Hans Betzhold y el psiquiatra y neurólogo portugués Egas Moniz, quien fuera Premio Nobel por descubrir el uso terapéutico de la lobotomía, son estudiados a través de sus obras más emblemáticas, cuyo enorme impacto se reflejó en las numerosas reediciones que tuvieron. Mientras Betzhold (1939), con su Eugenesia, se concentraba en alcanzar un "superhombre chileno", Moniz (1901), con su libro A vida sexual, aunó simbióticamente la eugenesia a la sexualidad, afianzando de este modo los tradicionales roles de género. Si, como muestran los trabajos ocupados aquí de la contracultura anarquista, ésta sustentó sus ideas eugénicas en una sexualidad disociada de la reproducción, de su íntima asociación derivaba, en cambio, un afianzamiento de las versiones más conservadoras de la institución familiar.

La normalización de la familia perduró en el tiempo, atravesando el marco de la Guerra Fría, cuando quedó consolidado un estereotipo como el promovido hasta entrada la década de 1970 por la Sociedad Argentina de Eugenesia, el cual es indagado en este número. Allí, los principios de la "ciencia de Galton" coincidirían hasta confundirse con los mandatos vaticanos, quedando los criterios de selección artificial presididos por la moralización de las costumbres y el determinismo ambiental.

De este modo, los trabajos conforman una constelación de aportes que interpelan a esta versión mediterránea y latinoamericana de la eugenesia, cuyas características incluyen las estrategias dirigidas a identificar, clasificar, jerarquizar y excluir la otredad. Con ese fin se persiguió la utopía de alcanzar una sociedad homogénea y armónica, eliminando el azar del proceso reproductivo de los seres humanos. Los diálogos entre Iglesia Católica y saberes científicos otorgarían singularidad al devenir de la eugenesia en esta región del mundo, convirtiéndola en un capítulo importante en la historia del siglo XX. Contribuir a ello ha sido el propósito de este número especial.

\section{REFERENCIAS}

ÁLVAREZ PELAEZ, Raquel.

Dossier: Estudios sobre eugenesia. Asclepio, v.51, n.2. 1999.
BETZHOLD, Hans.

Eugenesia. Santiago: Sociedad Imprenta y Litografía Universo. 1939. 
CAROL, Anne.

Histoire de l'eugénisme en France: les médicins et la procréation, XIXe-XXe siècle. Paris: Seuil. 1995.

MONIZ, Egas.

A vida sexual: fisiología. Coimbra: França Amado. 1901.
RICHET, Charles.

La sélection humaine. París: Alcan. 1919.

STEPAN, Nancy Leys.

The hour of eugenics: race, gender and nation in Latin America. Ithaca: Cornell University Press. 1991.

Marisa A. Miranda

Investigadora, Consejo Nacional de Investigaciones Científicas y Técnicas; profesora, Universidad Nacional de la Plata. La Plata - Buenos Aires - Argentina

Gustavo Vallejo

Investigador independiente, Consejo Nacional de Investigaciones Científicas y Técnicas, Departamento de Ciencias Sociales/Universidad Nacional de Quilmes. Bernal - Buenos Aires - Argentina 